\title{
SOBREVIVIENDO A REFORMAS, IMPOPULARIDAD \\ Y CASOS DE CORRUPCIÓN: EL PRESIDENCIALISMO DE COALICIÓN DEL BRASIL DE TEMER
}

\author{
Surviving Reforms, Unpopularity and Cases of Corruption: \\ The Brazilian Coalition Presidentialism of Temer
}

\author{
PEDRO FELIÚ \\ Universidad de São Paulo, Brasil
}

\begin{abstract}
RESUMEN
El año 2017 demostró la elevada capacidad del presidente brasileño para aprobar su agenda de gobierno y conformar un apoyo sólido y mayoritario en el Congreso Nacional. A pesar de enfrentar una coyuntura económica y social desfavorable, junto con una bajísima popularidad, Michel Temer aprobó una profunda reforma laboral y rechazó dos denuncias de corrupción en el Legislativo. Por medio de la distribución de ministerios a partidos aliados y la conformación de una coalición partidista ideológicamente homogénea, el presidente Temer demostró la gobernabilidad del presidencialismo de coalición brasileño. El cambio del statu quo, afectando incluso a la política exterior, ejemplificó el dominio del presidente en la política brasileña, principalmente en la capacidad para movilizar recursos en la delicada tarea de organizar una coalición partidaria de elevada fragmentación.
\end{abstract}

Palabras clave: Temer, reformas, presidencialismo de coalición, Brasil, 2017

\begin{abstract}
The year 2017 demonstrated the capacity the Brazilian president to approve his governmental agenda and secure solid, majority support in the National Congress. Despite the unfavorable economic and social situation, as well as very low popular support, Temer approved a deep labor reform and rejected denunciations of corruption in the legislative branch. Through the distribution of important ministries to allied parties and the formation of an ideologically homogeneous partisan coalition, President Temer demonstrated the governability of Brazilian coalition presidentialism. Recent policy changes, including to foreign policy, have exemplified the president's dominance in Brazilian politics, especially the ability to mobilize the resources of the office in the delicate task of organizing a coalition in a context of high party fragmentation.
\end{abstract}

Keywords: Temer, reforms, coalition presidentialism, Brazil, 2017 


\section{INTRODUCCIÓN}

En 2017, Brasil experimentó la combinación de distintos fenómenos. Por un lado, mostró un bajo crecimiento económico, alto déficit fiscal y desempleo, así como numerosas investigaciones por corrupción. Por otro lado, el gobierno del presidente Michel Temer (PMDB) tuvo una base sólida de apoyo en el Congreso Nacional. A pesar de la impopularidad y denuncias de corrupción contra Temer, el Poder Ejecutivo fue capaz de aprobar reformas significativas en muy poco tiempo. En palabras del expresidente Fernando Henrique Cardoso (1995-2002): "Temer hizo más cambios de lo que yo podía imaginar" (Azevedo 2017). Si la base de apoyo al gobierno se desplomó en 2016 durante la presidencia de Rousseff (2011-2016) (Nunes y Ranufo 2017), al año siguiente vio un presidente con una coalición de apoyo disciplinado y mayoritario que ha garantizado un alto éxito legislativo de las iniciativas presidenciales. Aun cuando la presidencia en Brasil tiene capacidad presupuestaria, administrativa y legislativa para construir el apoyo mayoritario, el contexto de un congreso con elevada fragmentación partidaria (Limongi 2006), la administración de esta coalición política es uno de los principales desafíos en la implementación de las políticas públicas del gobierno (Bertholini y Pereira 2017). El año 2017 fue testigo del elevado éxito del presidente Temer en esta tarea (Pereira 2017), hecho aún más impresionante dada la negativa coyuntura política, social y económica que caracterizó al país.

Al contrario del gobierno Temer, el gobierno anterior de Dilma Roussef (20112016) presentó grandes dificultades para articular su coalición e implementar sus políticas (Ribeiro et al. 2016). Después de la más apretada elección presidencial de la historia brasileña en 2014, Dilma enfrentó en el año siguiente un descenso de su popularidad dentro de un contexto de disonancia entre promesas de campaña, crisis económica y escándalos de corrupción (Ribeiro et al. 2016). El año 2016 estuvo marcado por la profundización de un escenario conturbado que culminó en el enjuiciamiento de Dilma Rousseff y una grave crisis de legitimidad de los principales partidos políticos (Nunes y Ranufo 2017). Ya en 2016, Temer impuso una nueva agenda con medidas ortodoxas para enfrentar los problemas económicos después de 13 años del mandato del PT, moviendo el gobierno hacia la derecha del espectro ideológico (Nunes y Ranufo 2017).

Este artículo tiene como objetivo central describir los principales acontecimientos políticos de Brasil en 2017 bajo la óptica del presidencialismo de coalición, variable política central del desempeño de Temer. Su intención principal radica en comprender cómo el presidente Temer logró aprobar una profunda reforma laboral, sobrevivir a dos denuncias de corrupción y efectuar cambios en la política exterior brasileña en un ambiente político y social tan adverso. El argumento central aquí desarrollado es que la fidelidad de la base mayoritaria del apoyo al gobierno en el congreso -elemento clave para el éxito legislativo del presidente- fue obtenida distribuyendo ministerios importantes entre partidos de la coalición del gobierno. Eso fue posible gracias a la baja heterogeneidad ideológica de los partidos que la componen. 
El artículo se estructura de la siguiente manera. En la primera sección se contextualiza el ambiente económico, social y político de Brasil en el año 2017. La segunda sección describe el contenido sustantivo de las principales materias legislativas en 2017, dimensionando el grado del impacto de las reformas de Temer en el país. En tercer lugar se analizan las principales variables presentes en la literatura sobre la composición de la coalición de gobierno en el presidencialismo, la distribución de cargos y recursos entre los partidos de la base del gobierno y la heterogeneidad ideológica de los partidos que apoyan a Temer. Finalmente se presentan unas consideraciones finales.

\section{EL CONTEXTO POLÍTICO, ECONÓMICO Y SOCIAL EN BRASIL EN 2017}

En 2015 y 2016, Brasil evidenció retracciones del 3,8\% y el 3,6\% de su PIB (IBGE 2017), respectivamente, atravesando una de las más agudas crisis económicas de su historia republicana. Aunque en el año 2017 algunos indicadores mejoraron sustancialmente — como es el caso del crecimiento del 1\% del PIB - aún perduraron reflejos negativos de la grave crisis económica reciente. Por ejemplo, el PIB per cápita del país continuó declinando (un 4,4 \%), lo que desnudó el escaso impacto que tuvo el 1\% de crecimiento del PIB bruto. Incluso, algunos estipulan que el retorno al crecimiento en 2017 puede explicarse por la reutilización de la capacidad ociosa resultante de tres años de grave crisis económica (Meirelles 2017). Así, la tímida recuperación del crecimiento económico no se tradujo en demasiado optimismo de parte de la sociedad civil (Gandra 2017). La tabla 1 resume los indicadores socioeconómicos más relevantes del año 2017 junto con sus respectivas variaciones anuales respecto de 2016.

Tabla 1. Indicadores socioeconómicos de Brasil en 2017

\begin{tabular}{lcc}
\hline \multicolumn{1}{c}{ INDICADOR } & 2017 & VARIACIÓN ANUAL (\%) \\
\hline Crecimiento económico (\%) & 1 & $+4,6$ \\
Déficit Fiscal (mil millones R\$) & 124 & -20 \\
Desempleo (\%) & 11,8 & -2 \\
Inflación (\%) & 3 & $-3,3$ \\
PIB/per cápita (R\$) & 30.407 & $-4,4$ \\
Pobreza (\%) & 25,4 & $+2,3$ \\
Superávit comercial (mil millones R\$) & 67 & +70 \\
Violencia urbana (homicidios/100 mil) & 28,9 & -2 \\
\hline
\end{tabular}

Fuente: IBGE (2017) 
Las inversiones públicas estuvieron claramente perjudicadas dado al elevado déficit fiscal del gobierno. Como ha sido demostrado en distintos estudios, esta es una variable clave en la historia del desarrollo económico del país (Orair 2016). Aunque el déficit fiscal en 2017 fue un $20 \%$ menor con respecto al año anterior, los 124 mil millones de reales negativos en el saldo de las cuentas del gobierno fueron un obstáculo mayor para la reanudación de la inversión pública en Brasil. Los efectos de la retracción económica previa se manifestaron en 2017, especialmente en el estrato de menores ingresos, reflejado en el aumento del 2,3\% en la proporción de personas viviendo con menos de dos dólares al día, lo que abarca a más de la cuarta parte de la población brasileña $(25,4 \%)$. Así, la reducción de la pobreza — principal bandera de los gobiernos federales anteriores-siguió sufriendo retrocesos en 2017.

La baja inflación (3\%) y el crecimiento de las exportaciones y superávit de la balanza comercial brasileña fueron elementos que trajeron algún optimismo en la recuperación de la economía. Sin embargo, dos indicadores de alta sensibilidad política y social permanecieron muy mal durante el 2017: el desempleo y la violencia urbana. El desempleo en el Brasil de 2017 continuó en un nivel muy elevado, casi $12 \%$, a pesar del retroceso del $2 \%$ con respecto al año anterior. Según un estudio de opinión a nivel nacional, el 56\% de la población brasileña evaluaba el desempleo como el principal problema del país, seguido de la corrupción (55\%), la salud (44\%) y la seguridad pública (36\%) (CNI 2018). ${ }^{1}$ Es razonable pensar que la elevada tasa de desempleo jugó un papel clave en la evaluación popular del presidente, principalmente en un año de profundas reformas en la ley laboral. A esto se le suman otros resultados negativos tales como las dos denuncias de corrupción contra Temer enviadas a la Cámara de Diputados en 2017 y registrar la undécima mayor tasa de homicidios del mundo (28,9 homicidios/100 mil). 
Figura 1. Aprobación popular del presidente Temer en 2017

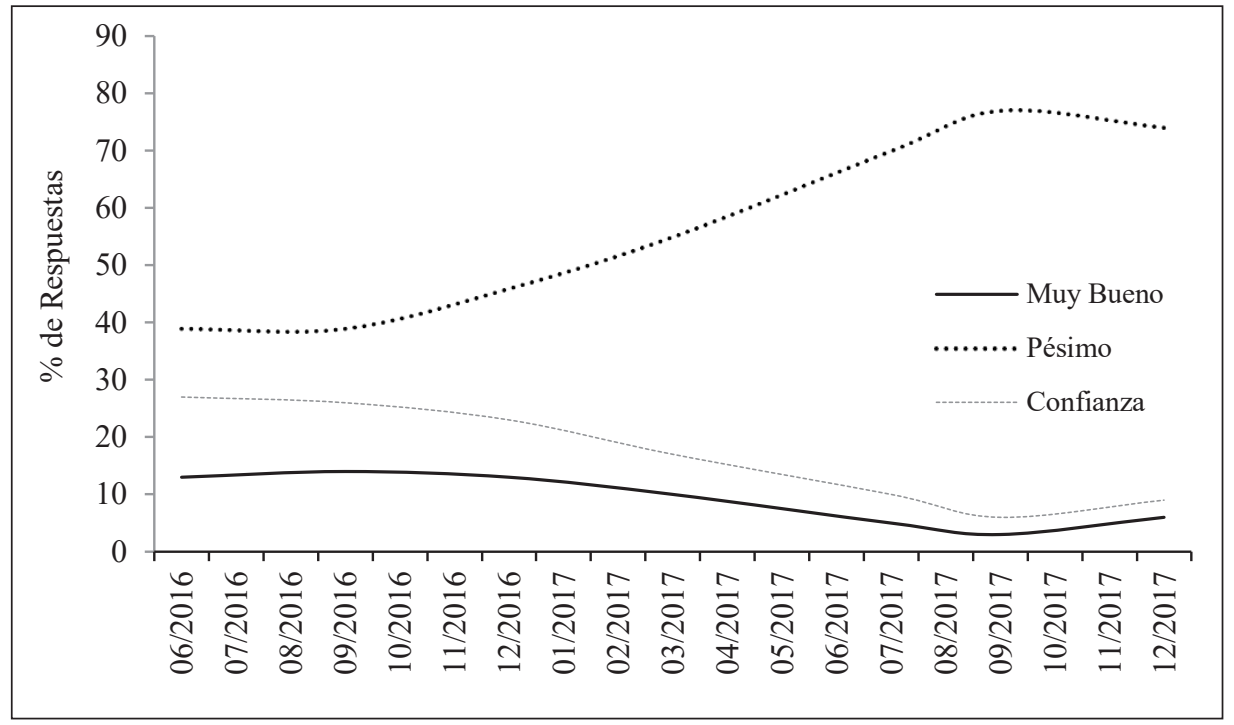

Fuente: CNI/Ibope (2018)

Como muestra la figura 1, desde el final de 2016 la confianza de la población en el presidente y su evaluación positiva sufrieron fuertes caídas. En septiembre de 2017 se tocó un piso de 3\% de evaluaciones "muy buenas" y de 6\% de personas afirmando tener confianza en el mandatario nacional. Al mismo tiempo, la peor evaluación posible del presidente, "pésimo", subió en el mismo período, alcanzando casi al $80 \%$ de la población.

Se podría especular que a mayor popularidad presidencial, mayor apoyo legislativo. Esta relación se sustentaría en la idea de que votar contra el presidente implicaría para los legisladores asumir un potencial elevado costo electoral (Rudalevige 2002). En la misma línea, una popularidad presidencial baja debería perjudicar la capacidad del presidente en recibir apoyo legislativo a sus propuestas. Aunque este tipo de relación positiva entre aprobación popular y éxito legislativo presidencial fue descrita en el presidencialismo brasileño (Mainwaring 1997), el caso del presidente Temer parece alejarse de esa relación. La siguiente sección describe las principales iniciativas legislativas en el año, señalando el contenido sustantivo de ellas y los respectivos resultados de aprobación en el Congreso Nacional.

\section{LAS REFORMAS Y LOS TRÁMITES LEGISLATIVOS}

A pesar de la elevada impopularidad, en 2017 el presidente Temer obtuvo importantes victorias políticas en el Congreso Nacional en votaciones de alto impacto. En ese año se tramitaron en el Legislativo la reforma laboral y ley de la tercerización, dos denuncias de corrupción enviadas por la Procuraduría 
General de la República (PGR) a la Cámara de Diputados, la reforma política y concesiones públicas al sector privado. La tabla 2 resume los temas con sus respectivos resultados en las cámaras legislativas brasileñas.

Tabla 2. Principales Tramitaciones y los votos legislativos en 2017

\begin{tabular}{|c|c|c|c|c|c|c|}
\hline \multirow[b]{2}{*}{ FECHA } & \multirow[b]{2}{*}{ MATERIA } & \multirow[b]{2}{*}{ DESCRIPCIÓN } & \multicolumn{2}{|c|}{ CÁMARA } & \multicolumn{2}{|c|}{ SENADO } \\
\hline & & & SI & No & SI & No \\
\hline $22 / 03 / 2017$ & Tercerización & Tercerización laboral & 231 & 188 & - & - \\
\hline $27 / 04 / 2017$ & Laboral & $\begin{array}{c}\text { Flexibiliza las leyes } \\
\text { laborales }\end{array}$ & 296 & 177 & 50 & 26 \\
\hline $06 / 05 / 2017$ & Concesiones & $\begin{array}{c}\text { Privatización sectores de } \\
\text { infraestructura }\end{array}$ & 284 & 99 & 48 & 19 \\
\hline 02/08/2017 & $\begin{array}{c}\text { Denuncia Temer } \\
\text { I }\end{array}$ & Corrupción pasiva & 263 & 277 & - & - \\
\hline $04 / 10 / 2017$ & Política & $\begin{array}{l}\text { Nuevas reglas de finan- } \\
\text { ciación de campaña }\end{array}$ & 223 & 209 & - & - \\
\hline $05 / 10 / 2017$ & Política & $\begin{array}{c}\text { Prohibición de las coliga- } \\
\text { ciones }\end{array}$ & 384 & 16 & 62 & 0 \\
\hline $25 / 10 / 2017$ & $\begin{array}{c}\text { Denuncia Temer } \\
\text { II }\end{array}$ & Obstrucción judicial & 251 & 233 & - & - \\
\hline
\end{tabular}

Fuente: http:/ /www2.camara.leg.br/ y https://www12.senado.leg.br/hpsenado

A comienzos de año, dos cambios en la ley laboral brasileña generaron mucha polémica y tuvieron gran repercusión en los medios y el debate público. El primer cambio fue la aprobación en la Cámara de Diputados, en marzo de 2017, de la ley de la tercerización de todas las actividades laborales. La estrategia de Temer fue resucitar un proyecto de ley propuesto por el gobierno de Fernando Henrique Cardoso en 1998, ya aprobado en el Senado hacía 16 años. Por tal motivo, el proyecto de ley no precisó de tramitación en el Senado siendo suficiente para la sanción presidencial la aprobación en Diputados.

Ese proyecto de ley permite la tercerización de cualquier actividad de una empresa, además de aumentar a seis meses el permiso de trabajo temporal. El statu quo provenía de entendimiento del Tribunal Superior del Trabajo, acta 331 de 2003, cuyo dispositivo determinaba que la tercerización solo fuera posible en actividades que no son el objetivo principal de una empresa, llamada "actividad fin". Por ejemplo, una universidad podía subcontratar el servicio de limpieza, transporte, mantenimiento, entre otros, según la interpretación vigente hasta entonces. Con la aprobación de la ley de tercerización, esa misma universidad puede subcontratar también docentes, eso es, personal para llevar adelante su propia actividad fin. El apoyo a la ley suscitó la oposición entre empleadores y empleados en el país, como quedó en evidencia, por ejemplo, en 
los posicionamientos favorables de la Confederación Nacional de la Industria (CNI) y contrario de la Central Única de Trabajadores (CUT). ${ }^{2}$ En la Cámara de Diputados, 231 votos favorables contra 188 contrarios fueron suficientes para aprobar la ley sancionada por el presidente.

Al dar continuidad a su agenda política de reformas pro-mercado, Temer inició el trámite del proyecto de ley de la Cámara PLC 38/2017, conocido como Reforma Laboral. El texto aprobado en ambas cámaras con holgada mayoría otorgaba mayor peso a lo acordado entre empleados y empleadores, siendo posible reglamentar dieciséis elementos de la ley como, por ejemplo, plan de puestos e intervalo intrajornada. Otros 29 puntos permanecen imposibles de ser modificados por medio del acuerdo entre empleadores y empleados, como el sueldo mínimo, vacaciones y licencia por maternidad.

Otras cuestiones tales como la duración de la jornada laboral (flexibilizada para 12 horas), el banco de horas, la subdivisión de vacaciones (en hasta tres veces) y los turnos laborales pueden ser negociadas directamente con el superior del empleado, haciendo innecesaria la presencia de un sindicato en dicho trámite. Otro punto relevante de la reforma laboral es el fin de la contribución sindical obligatoria, responsable en 2016 de la recaudación de $\mathrm{R}$ \$ 3,5 mil millones, sumada las contribuciones patronales y laborales (Ministerio de Trabajo 2017).

La reforma laboral promovida en 2017 por el gobierno Temer se propuso atacar el desempleo, principal problema de Brasil en la percepción de los ciudadanos. La expectativa del gobierno era acelerar la creación de empleos al flexibilizar algunas reglas laborales, generando menor costo para los empresarios en la contratación de mano de obra. En 2017, el saldo entre creación y cierre de puestos de trabajo fue negativo, con un resultado negativo de aproximadamente 21 mil puestos de trabajo, teniendo el sector de la construcción civil el mayor déficit (Ministerio de Trabajo 2018). Sin embargo, fue el mejor resultado de los últimos tres años, que acumulan juntos la pérdida de 2,8 millones de puestos de trabajo. Muchas críticas a la reforma de Temer utilizaron el caso de la reforma laboral en España, modelo que sirvió de inspiración para la reforma brasileña. El resultado de la reforma en el país ibérico, ocurrida en 2012, disminuyó el elevado desempleo español por medio de la generación de empleos precarios con salarios menores, empeorando la calidad de vida del trabajador en los estratos más populares de la sociedad (Gómez 2017).

La Medida Provisional (MP) 752/16 es otro importante proyecto aprobado durante la gestión de Temer que beneficia directamente al sector empresarial. El punto principal de esta iniciativa es la prorrogación de contratos de asociación entre gobierno y sector privado en los sectores de carreteras, ferrocarril y aeroportuario. Así como en la reforma laboral, la Medida Provisional de las concesiones obtuvo amplia mayoría en ambas cámaras legislativas, mostrando

2 Portal G1. [En línea]. < https://g1.globo.com/economia/noticia/reforma-trabalhista-opoe-cni-e-cut-veja-o-que-pensam-empresarios-e-trabalhadores.ghtml>. [Consulta: 06/04/2018]. 
una vez más la fuerza del presidente en el Congreso Nacional. El punto más polémico de la iniciativa es la licitación de los contratos de concesión cuyo incumplimiento de las obligaciones asumidas se debiera a la incapacidad de los socios. En la evaluación del gobierno, la medida debe estimular a las agencias reguladoras o entidades competentes para incorporar nuevas tecnologías, servicios e incluso inversiones en contratos prorrogados o reciclados, además de dar más eficiencia a los contratos y "ánimo" a las inversiones para evitar su paralización (Esposito 2017). La oposición, sin embargo, argumentó que la medida es un "cheque en blanco" al sector privado y que el Congreso Nacional terminó aprobando concesiones de más de 30 años sin licitación (Esposito 2017).

La reforma política aprobada en 2017 consiste de dos partes legislativas: el proyecto de la Cámara PLC 110/2017 y la propuesta de enmienda a la constitución PEC 33/2017. La primera, de autoría del diputado federal Vicente Cândido (PT-São Paulo), modifica las reglas para el financiamiento de las campañas políticas, así como la creación del Fondo Especial de Financiamiento de Campaña con R 1,7 mil millones de dinero público para las elecciones de 2018. La nueva ley sigue la decisión del Supremo Tribunal Federal (STF) sobre la inconstitucionalidad de la donación de personas jurídicas para campañas electorales, prohibiendo candidaturas independientes y estableciendo límites de gastos para los cargos ejecutivos y legislativos resumidos en la tabla 3.

Tabla 3. Límite de gastos en campaña política por puesto

\begin{tabular}{cc}
\hline Puesto & LÍmite \\
\hline Presidente & $\mathrm{R} \$ 70 \mathrm{mi}$ \\
Gobernador* $^{*}$ R $2,8 \mathrm{mi}$ a $\mathrm{R} \$ 21 \mathrm{mi}$ \\
Senador* & $\mathrm{R} \$ 2,5 \mathrm{mi}$ a $\mathrm{R} \$ 5,6 \mathrm{mi}$ \\
Diputado Federal & $\mathrm{R} \$ 2,5 \mathrm{mi}$ \\
Diputado Estadual & $\mathrm{R} \$ 1 \mathrm{mi}$ \\
\hline
\end{tabular}

* Los limites varían conforme el tamaño del electorado Fuente: http:/ /www2.camara.leg.br/

A diferencia de la reforma laboral, analizada anteriormente, la reforma política aprobada en octubre de 2017 tuvo una votación bastante apretada en la Cámara de Diputados (223 votos favorables y 203 contrarios) y una aprobación simbólica en el Senado. El proyecto aprobado en el Congreso Nacional sufrió vetos del presidente Temer en cuatro puntos, manteniendo la posibilidad de que el candidato se autofinancie, eliminando la censura en internet sobre difamación y estableciendo un límite para donación de personas físicas del 10\% de los rendimientos brutos declarados el año anterior a la elección. Uno de los principales aspectos de la ley es la distribución de los recursos públicos para financiamiento de campaña: un $2 \%$ igualitario entre todos los partidos; un $35 \%$ 
entre los partidos con al menos un representante en la Cámara de Diputados, proporcionalmente a los votos obtenidos por ellos en la última elección para la Cámara de Diputados; un 48\% entre los partidos en la proporción de diputados en la Cámara el 28 de agosto de 2017 y el 15\% restante entre los partidos en la proporción del número de senadores el 28 de agosto de 2017. Los límites impuestos a la contribución de campaña fueron un intento de los parlamentarios de dar una respuesta al creciente descontento de la población con la corrupción y la clase política. Aunque no es una medida del presidente, contó con la participación de este en la producción legislativa final.

La otra propuesta aprobada que conforma la reforma política de 2017 fue la enmienda que acaba con las coaliciones partidarias en las elecciones a partir de 2020 y les crea una cláusula de barrera para acceder al fondo partidario y al tiempo de propaganda gratuita en la radio y televisión a partir de 2018. Las barreras aprobadas siguen un cronograma de aumento progresivo. Los partidos deben obtener en las elecciones para diputados federales al menos el 1,5\% de los votos válidos, en al menos un tercio de los Estados, además de al menos el 1\% de los votos válidos en cada Estado. En las elecciones de 2022, siempre para la elección de diputados federales, los partidos necesitarán al menos el 2\% de los votos válidos, distribuidos en al menos un tercio de las unidades de la federación, con al menos el 1\% de los votos válidos en cada una de ellas. En 2026 será al menos el 2,5\% de los votos válidos, distribuidos en el mismo tercio de los Estados y en 2030 llega al 3\% de los votos válidos distribuidos en un tercio de los Estados con al menos el 2\% de los votos válidos en cada uno de ellos. Además de los criterios mencionados, los partidos también pueden sobrepasar la cláusula de barrera eligiendo al menos 9 diputados en 2018, 11 en 2022, 13 en 2026 y 15 en 2030, siempre distribuidos en al menos un tercio de las unidades de la federación.

Brasil tuvo un número efectivo de partidos de 14,06 en las elecciones de 2014; el mayor índice en el mundo (QoG Institute 2015). En el intento por disminuir ese elevado número de partidos en el Congreso Nacional, los legisladores, con el apoyo de Temer, buscaron crear cláusulas de barrera para disminuir de manera efectiva del número de partidos, aun más en un escenario de fuerte restricción en el monto permitido en las campañas electorales a partir de 2018. La propuesta obtuvo apoyo masivo tanto en la coalición que sustenta al gobierno como en la oposición, componiendo otra de las respuestas del Congreso al electorado en relación con la insatisfacción sobre la clase política.

La percepción de la corrupción como principal problema del país y la baja popularidad del presidente se reflejan en las dos denuncias de corrupción contra Temer enviadas a la Cámara de Diputados. La primera denuncia fue elaborada por el procurador general de la República, Rodrigo Janot, cuyo contenido esencial era el pago indebido de medio millón de reales a cambio de favores a la empresa JBS. Para el encaminamiento de la denuncia al Supremo Tribunal Federal (STF), la primera en la historia brasileña, eran necesarios 342 votos. Si la denuncia en el STF era acatada, Temer sería desplazado de la presidencia hasta 
ser juzgado. En una votación bastante polarizada y cerrada, 277 legisladores fueron contrarios a la aceptación de la denuncia y 263 favorables. Aunque la victoria de Temer haya sido sorprendente, comenzaron a sentirse el peso de su impopularidad y el rechazo a la corrupción. Una parte significativa de los diputados que rechazaron la denuncia justificó su posición resaltando la prioridad en recuperar la economía a partir de las reformas estructurales realizadas por Temer (Câmara dos Deputados 2017). Es importante señalar que 91 legisladores, entre senadores y diputados, estaban acusados por la operación Lava Jato, la misma que propició la denuncia contra el presidente.

La segunda denuncia, también elaborada por el procurador general de la República, Rodrigo Janot, acusaba al presidente de ejercer el papel de líder de una organización criminal en el esquema de corrupción revelado en la Lava Jato. En la denuncia, se alegaba obstrucción a la justicia por parte de Temer, acusado de instigar al empresario Joesley Batista, dueño de JBS, a pagar al exdiputado Eduardo Cunha (PMDB-Río de Janeiro) para evitar su delación compensada. Esta última acusación fue fundada en una conversación grabada entre Temer y el empresario en marzo de 2017 en el palacio presidencial. La Procuraduría General de la República (PGR) estimó en R 587 millones los desvíos desde el Poder Ejecutivo destinados al PMDB, partido del presidente. Una vez más, una mayoría cualificada era necesaria para aceptar la denuncia contra el primer mandatario.

Aunque los votos favorables no fueron suficientes, a diferencia de la primera denuncia, los votos contrarios a la aceptación fueron menores que los favorables, con un apretado resultado de 251 a 233. Esta votación demostró la creciente dificultad de Temer para sobrevivir en un ambiente político y social desfavorable a su gobierno. Sin embargo, frente a los enormes desafíos impuestos por escándalos de corrupción provenientes de una importante investigación comandada por la Política Federal y el Ministerio Público Federal y la elevada insatisfacción popular, Temer fue capaz de movilizar eficientemente los recursos disponibles para inducir una mayoría en el Congreso Nacional. La base mayoritaria de apoyo en el Congreso fue capaz de garantizar al presidente la supervivencia en su cargo y la aprobación de contundentes reformas como la laboral. La siguiente sección analiza los principales elementos asociados con el éxito legislativo de Temer y explora aspectos centrales del presidencialismo de coalición brasileño: los nombramientos ministeriales, el grado de cohesión de la coalición partidaria de apoyo al gobierno y la utilización del presupuesto.

\section{EL PRESIDENCIALISMO DE COALICIÓN EN BRASIL EN 2017}

En un presidencialismo multipartidario, la formación de coaliciones es un fenómeno común. Esto sucede ante la dificultad que el partido del presidente usualmente tiene a la hora de conquistar la mayoría de los asientos en el Congreso Nacional (Chasquetti 2001; Cheibub et al. 2004). La combinación 
entre presidencialismo y multipartidismo ya fue considerada a principios de los años noventa del siglo pasado como propensa a la inestabilidad, pues amenazaba la supervivencia de los nuevos regímenes democráticos en la región (Mainwaring 1993; Stepan y Skach 1993). Las previsiones pesimistas en relación con la estabilidad de los regímenes presidencialistas multipartidistas, sin embargo, no se concretaron (Pereira y Melo 2012), aunque acabarían siendo un marco institucional caracterizado por la presencia de regímenes estables pero presidentes inestables (Pérez-Liñán y Polga-Hecimovich 2012).

El presidencialismo multipartidario de Brasil es descrito como un presidencialismo de coalición (Abranches 1988), con un presidente capaz de incentivar la formación de una coalición partidaria mayoritaria en el Congreso Nacional a través de sus elevados poderes legislativos, administrativos y presupuestarios (Chaisty et al. 2014). El presidencialismo de coalición ha sido descrito como un sistema eficaz en lo que se refiere a la capacidad de gobernar del presidente, generalmente produciendo un alto nivel de éxito legislativo del Ejecutivo no sólo en Brasil (Figueiredo y Limongi 1999; Freitas 2016), sino también en casos similares como el chileno (Arcaya 2003; Nolte 2003) y uruguayo (Chasquetti 2008). Los elementos relevantes en el análisis de la capacidad de gobernar del presidente en este arreglo institucional involucran los nombramientos a cargos en la administración federal (Batista 2013), la distancia ideológica de los partidos que componen la base del gobierno (Santos et al. 2014) y la utilización del presupuesto en la forma de ejecución de las enmiendas parlamentarias (Pereira y Mueller 2002). Como la formación de una mayoría legislativa es un elemento crucial para la estabilidad de un gobierno en el presidencialismo multipartidista (Negretto 2006), a continuación se analiza la composición de la base de apoyo al gobierno en el Legislativo en 2017.

\section{El apoyo en el Congreso Nacional}

Según Amorim Neto (2006), el presidente elabora su estrategia de negociación con el Congreso Nacional en función del tipo de agenda legislativa que pretende implementar. Una agenda legislativa que necesita aprobación del Congreso por medio de proyectos de ley y enmiendas constitucionales demanda una elevada partidización y coalescencia en la composición del gobierno. Este es precisamente el caso del gobierno Temer en 2017. Como vimos en la sección anterior, los cambios promovidos por el Ejecutivo así como la propia supervivencia del presidente exigieron apoyo parlamentario. La tabla 4 expone las proporciones de las bancadas de los partidos y coaliciones en la Cámara de Diputados (CD) y Senado (SN), así como el porcentaje promedio de las veces en que los diputados de cada partido votaron alineados con la indicación del gobierno. Es importante subrayar que las proporciones de bancadas por partido presentadas en la tabla 4 tienen en cuenta el resultado de las elecciones de 2014. Sin embargo, en el transcurso de la legislatura 2015-2018, algunos legisladores cambiaron de partido, modificando un poco la distribución referida. Por ejemplo, en el año 
2017, el PT se redujo de 70 diputados a 52, el PMDB de 66 diputadas a 57 y el PSDB de 54 a 46. El DEM, por otro lado, creció de 22 a 36 diputados. ${ }^{3}$

Tabla 4. Tamaño y apoyo al gobierno de las coaliciones partidistas en 2017

\begin{tabular}{|c|c|c|c|c|}
\hline COALICIÓN & Partido & CÁMARA & SEnAdo & $\begin{array}{c}\text { VOTOS CON EL GOBIER- } \\
\text { NO }\end{array}$ \\
\hline \multirow{13}{*}{ Gobierno } & DEM & $4,3 \%$ & $6,2 \%$ & $96 \%$ \\
\hline & PMDB & $12,9 \%$ & $22,2 \%$ & $95 \%$ \\
\hline & PSDB & $10,5 \%$ & $12,3 \%$ & $93 \%$ \\
\hline & PP & $7,0 \%$ & $6,2 \%$ & $93 \%$ \\
\hline & PSL & $0,2 \%$ & $0,0 \%$ & $93 \%$ \\
\hline & PSD & $7,2 \%$ & $3,7 \%$ & $92 \%$ \\
\hline & PRP & $0,6 \%$ & $0,0 \%$ & $92 \%$ \\
\hline & PRB & $4,1 \%$ & $1,2 \%$ & $91 \%$ \\
\hline & PEN & $0,4 \%$ & $0,0 \%$ & $89 \%$ \\
\hline & PR & $6,6 \%$ & $4,9 \%$ & $88 \%$ \\
\hline & РТВ & $4,9 \%$ & $3,7 \%$ & $88 \%$ \\
\hline & SD & $2,9 \%$ & $1,2 \%$ & $86 \%$ \\
\hline & PSC & $2,3 \%$ & $0,0 \%$ & $85 \%$ \\
\hline Total & & $64,0 \%$ & $62,0 \%$ & $91 \%$ \\
\hline \multirow{10}{*}{ Oposición } & PPS & $1,9 \%$ & $0,0 \%$ & $84 \%$ \\
\hline & PROS & $2,1 \%$ & $1,2 \%$ & $82 \%$ \\
\hline & PV & $1,6 \%$ & $1,2 \%$ & $81 \%$ \\
\hline & PSB & $6,6 \%$ & $8,6 \%$ & $72 \%$ \\
\hline & PHS & $1,0 \%$ & $0,0 \%$ & $72 \%$ \\
\hline & PTN & $0,8 \%$ & $0,0 \%$ & $70 \%$ \\
\hline & PDT & $3,7 \%$ & $9,9 \%$ & $44 \%$ \\
\hline & PT & $13,6 \%$ & $14,8 \%$ & $24 \%$ \\
\hline & PCdoB & $1,9 \%$ & $1,2 \%$ & $24 \%$ \\
\hline & PSOL & $1,0 \%$ & $1,2 \%$ & $9 \%$ \\
\hline Total & & $34,0 \%$ & $38,0 \%$ & $56 \%$ \\
\hline
\end{tabular}

Fuente: TSE (2014) y Estadão Dados Basômetro (2018) 
En 2017, el presidente Temer tuvo un apoyo legislativo en la Cámara y Senado del $64 \%$ y el $62 \%$ de los escaños, respectivamente, garantizando una amplia mayoría en el Congreso Nacional. Durante el año 2017, el PPS, PSB, PV y PTN abandonaron la base de apoyo al presidente Temer en función de los desdoblamientos de la operación Lava Jato y los casos de corrupción que involucraron su figura, casos que se convertirían en dos denuncias formales. Sin embargo, Temer logró mayoría en las principales materias legislativas de 2017, como fue mencionado en la sección anterior. Adicionalmente, cuando se consideran todas las votaciones nominales en la Cámara de Diputados en 2017, se puede observar la elevada fidelidad de la coalición de gobierno (ver la última columna de la tabla 4). La fidelidad es el resultado de la división del número de votos progobierno por el total de votos dados en el período por el mismo parlamentario, extrayendo las medias de los parlamentarios por partido político (Estadão Basômetro 2018).

Mientras la coalición gubernamental votó de acuerdo con la indicación del gobierno el $91 \%$ de las veces, en promedio, la oposición votó solo el $56 \%$ de las veces a favor de este. Los partidos de izquierda como el PT, PCdoB y PSOL presentaron el mayor de grado de oposición al presidente Temer, con apenas $24 \%$, 24\% y 9\%, respectivamente, de votos coincidentes con la indicación gubernamental. Entre los casos de los partidos más fieles al gobierno y con mayor representación política en el Congreso están el DEM (96\%), el PMDB (95\%), PSDB (93\%), PP (93\%) y PSD (92\%). Todos estos partidos obtuvieron de Temer importantes puestos ministeriales, componiendo el núcleo duro de su gobierno. Por ello, es importante analizar la distribución ministerial por partido y relevancia de los ministerios en el cálculo político que tuvo lugar durante el año 2017.

\section{La distribución de cargos en la coalición de gobierno}

La lógica central que conecta el apoyo legislativo a la distribución de cargos ministeriales es el cambio de este apoyo por influencia en el gobierno, es decir, como representante de un partido, el ministro o ministra tiene una ideología, preferencias políticas, proyectos electorales y agenda política propia que serán negociados en la formulación de las políticas públicas del gobierno (Batista 2013). En este sentido, la elección de personas vinculadas con los partidos políticos que apoyan al presidente o primer ministro es un método común en distintos gobiernos alrededor del mundo (Dahlström y Niklasson 2013). Hay una gran variedad de estudios de caso y comparados que apuntan a la relevancia de la variable partidista en la elección ministerial (Blondel 1988; Mayntz y Derlien 1989; Rauch y Evans 2000; Eichbaum y Shaw 2007; Lewis 2007).

En Brasil, los estudios también demuestran la relevancia de los nombramientos políticos de los ministerios, principalmente en la configuración del apoyo que los presidentes reciben en el Poder Legislativo (Amorim Neto 2006). La tabla 5 expone el grado de relevancia de los ministerios brasileños, los partidos que 
ocuparon la cartera en el año 2017 así como la existencia o no de investigaciones de corrupción respecto de las personas nombradas por el presidente Temer.

Tabla 5. Distribución ministerial del Gobierno Federal 2017

\begin{tabular}{|c|c|c|c|c|c|}
\hline 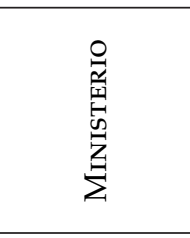 & $\begin{array}{l}0 \\
0 \\
0 \\
0 \\
5 \\
5 \\
0\end{array}$ & 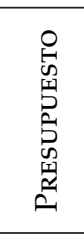 & 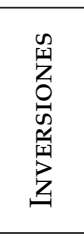 & \begin{tabular}{l}
$\stackrel{0}{0}$ \\
$\stackrel{0}{E}$ \\
\multirow{2}{*}{}
\end{tabular} & 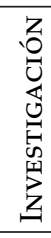 \\
\hline Economía & 0,88 & 0,60 & 0,04 & PSD & no \\
\hline Salud & 0,64 & 0,75 & 0,28 & PP & sí \\
\hline Justicia & 0,54 & 0,45 & 0,06 & $\begin{array}{l}\text { PMDB/PSDB/ } \\
\text { Sin Partido }\end{array}$ & sí \\
\hline Planificación & 0,51 & 0,48 & 0,06 & PMDB/PMDB & sí \\
\hline Educación & 0,32 & 0,68 & 0,24 & DEM & sí \\
\hline $\begin{array}{l}\text { Ciencia y } \\
\text { Tecnología }\end{array}$ & 0,30 & 0,41 & 0,05 & PSDB & sí \\
\hline $\begin{array}{l}\text { Medio Am- } \\
\text { biente }\end{array}$ & 0,28 & 0,34 & 0,05 & PV & no \\
\hline Agricultura & 0,28 & 0,49 & 0,05 & PP & sí \\
\hline Cultura & 0,21 & 0,18 & 0,02 & $\begin{array}{l}\text { PMDB/PPS/Sin } \\
\text { Partido }\end{array}$ & no \\
\hline Defensa & 0,20 & 0,72 & 0,26 & PPS & sí \\
\hline Transportes & 0,16 & 0,56 & 0,58 & PR & sí \\
\hline Trabajo & 0,16 & 0,68 & 0,01 & РTB & sí \\
\hline Desarrollo & 0,15 & 0,28 & 0,01 & PRB & sí \\
\hline $\begin{array}{l}\text { Desarrollo } \\
\text { Social }\end{array}$ & 0,14 & 0,68 & 0,06 & PMDB & sí \\
\hline $\begin{array}{l}\text { Integración } \\
\text { Regional }\end{array}$ & 0,13 & 0,48 & 0,24 & PMDB & sí \\
\hline $\begin{array}{l}\text { Minas e } \\
\text { Energía }\end{array}$ & 0,11 & 0,34 & 0,01 & PSB & no \\
\hline $\begin{array}{l}\text { Relaciones } \\
\text { Exteriores }\end{array}$ & 0,09 & 0,26 & 0,00 & PSDB/PSDB & sí \\
\hline Turismo & 0,05 & 0,26 & 0,10 & PMDB/PMDB & sí \\
\hline Ciudades & 0,03 & 0,50 & 0,38 & $\mathrm{PSDB} / \mathrm{PP}$ & sí \\
\hline Deporte & 0,03 & 0,22 & 0,06 & PMDB & sí \\
\hline Casa Civil & - & - & - & PMDB & sí \\
\hline $\begin{array}{l}\text { Derechos } \\
\text { Humanos }\end{array}$ & - & - & - & PSDB & no \\
\hline
\end{tabular}

Fuente: elaboración propia a partir de datos de Batista (2017) y http:/ /www.brasil.gov.br/ 
Para establecer el grado de relevancia de los ministerios, aquí se utilizó la estimación de Batista (2017) en tres dimensiones relevantes para el interés de los partidos y políticos en la ocupación de la cartera: presupuesto, cargos y capacidad de inversión. El índice varía de 0 a 1, donde 1 es la máxima puntuación del criterio. Los cargos son relevantes para los políticos dado que posibilitan distribuir beneficios a aliados y construir apoyo electoral por medio de nombramientos. Así, cuanto más y mejores cargos disponibles en el ministerio, más atractivas se tornan estas posiciones. En este aspecto, el Ministerio de Economía posee una mayor cantidad de cargos a disposición del ministro, seguido por Salud, Justicia, Planificación y Educación. En 2017, estos ministerios estuvieron ocupados por PSD, PP, PSDB, PMDB y DEM. En el ámbito presupuestario, variable importante en lo que se refiere a la importancia del ministerio en el Gobierno Federal, los mayores presupuestos son de los ministerios de Salud, Defensa, Educación, Trabajo y Desarrollo Social, ocupados, respectivamente, por PP, PPS, DEM, PTB y PMDB. Por último, la capacidad de inversión del ministerio revela la posibilidad del político de liderar la implementación de la política pública con un elevado potencial de impacto positivo en el electorado, maximizando los votos. En este criterio, tenemos el Ministerio de Transportes (ocupado por el PR) con mayor capacidad de inversión, seguido por Ciudades (ocupado por el PSDB y PP), Salud, Defensa y Educación.

La descripción anterior, sumada a las informaciones contenidas en la tabla 4, sugiere una significativa correspondencia entre la relevancia del ministerio y la fidelidad legislativa de los partidos en relación con las propuestas apoyadas por el gobierno. Con excepción del PPS, que dejó el gobierno y presentó aun una fidelidad del $84 \%$ con él, todos los partidos favorecidos con ministerios relevantes demostraron un elevado apoyo al gobierno en el plenario, corroborando argumentos de la literatura acerca de la relevancia de la distribución ministerial en la construcción de una coalición partidista disciplinada. La ocupación de ministerios relevantes por partidos que no son el del presidente constituye un elemento clave para la construcción de un apoyo mayoritario y disciplinado al gobierno. La descripción anterior revela una distribución bastante generosa a partidos que no son el del presidente en ministerios relevantes, lo que presenta una elevada proporcionalidad de partidos de la coalición de Temer en ministerios en comparación con las gestiones pasadas (Pereira 2017).

Un ministerio que llama la atención en la lógica expuesta arriba es el de Relaciones Exteriores (MRE). Rompiendo con la práctica de los dos gobiernos anteriores, de nombrar a diplomáticos de carrera para el cargo, Temer nombró a José Serra (PSDB-São Paulo) y luego a Aloysio Nunes (PSDB- São Paulo) para el puesto. El primero renunció alegando problemas de salud. El MRE es un ministerio con bajo presupuesto, baja capacidad de inversión y relativamente pocos cargos comisionados disponibles, lo que podría indicar desinterés político por esa posición. Sin embargo, posee cierta visibilidad y prestigio en el escenario nacional (Batista 2017), lo que puede atraer a políticos relevantes de un importante partido en la base de apoyo al gobierno. Con el mando político 
y no diplomático, se esperaban cambios en la política exterior brasileña en el período. Dos acciones centrales la caracterizaron en 2017: la candidatura oficial a la OCDE (Organización para la Cooperación y Desarrollo Económico) y la suspensión de Venezuela del MERCOSUR.

La primera presentó cierto grado de continuidad en los esfuerzos del país en acercarse a organizaciones internacionales, aunque puede considerarse un cambio en los rumbos de la política exterior. En 1994 el país se asoció con la OCDE y en 2007, durante la gestión del presidente Lula (2003-2010), Brasil firmó una asociación estratégica con la organización. Aunque Brasil es un miembro observador en la OCDE y tiene acuerdos con ella, la adhesión formal como miembro pleno puede significar un rumbo contrario al de la búsqueda de un liderazgo en el Tercer Mundo, elemento relevante de la política exterior brasileña de distintos gobiernos (Soares de Lima 2005). Así, el excanciller de Lula, Celso Amorim (2003-2010) llegó a afirmar en 2007: “Entrar en la OCDE no es una reivindicación ni una aspiración de Brasil" (Fernandes 2017). El senador Roberto Requião (PMDB-Paraná), reaccionando al anuncio del gobierno sobre la candidatura a la OCDE, explicitó su contrariedad en función del alejamiento del Tercer Mundo que la acción simbolizaba:

...a entrada na OCDE poderia, eventualmente, vir acompanhada da exigência de que o país se afastasse do G77+China, que reúne, sob a liderança do Brasil, países em desenvolvimento e países pobres. Foi exatamente essa liderança do Brasil sobre o G77 que nos deu a projeção internacional de anos atrás. Com essa liderança, o Brasil pode sentar à mesa dos grandes, dos 20 mais ricos, dos 35 mais ricos, dos sete mais ricos. Mas como o novo Itamarati, os banqueiros Meirelles e Goldfajn, e o deslumbrado presidente da República não gostam de pobres, querem ver o nosso país afastado da África, da Ásia, da América Latina e Caribe, da Ásia e da Oceania, renunciando o protagonismo na política internacional, para se transformar em um lambe-botas dos ricos (Requião 2017). ${ }^{4}$

En la visión del gobierno brasileño, sin embargo, la adhesión a la OCDE significa plegarse a las mejores prácticas internacionales, favoreciendo el ambiente de negocios y a los inversores. La adhesión impulsaría las reformas implementadas por Temer en el ámbito doméstico, principalmente la reforma laboral y el intento de modificar la previsión, lo que revela la similitud de posicionamiento ideológico de la OCDE y Temer en relación con la política económica. Aunque las opciones OCDE y G77 no son tan claramente excluyentes, se puede afirmar que Temer busca profundizar la relación de Brasil con los países desarrollados, denotando un cambio de orientación hacia la política sur-sur vigente hasta entonces. 
La suspensión de Venezuela del MERCOSUR implica un cambio significativo en relación con el gobierno anterior. Recién ingresada en el bloque regional, Venezuela contaba con el apoyo firme de las administraciones del PT, que se negaron a interferir u opinar sobre la situación interna del país. En la política exterior de Temer, Serra y Nunes, Brasil pasó a ser crítico de la falta de democracia en el país vecino, distanciándose políticamente de Caracas. A finales de 2016 y principios de 2017, los cuatro miembros permanentes del MERCOSUR consideraron que Venezuela no cumplía el protocolo de adhesión aprobado en 2006. Entre otros aspectos, la adhesión al arancel externo común por parte del país caribeño no sigue los plazos previstos, justificando la suspensión temporal de sus derechos en el arreglo regional de integración. La conducción de Itamaraty por políticos del PSDB y el compromiso presidencial con una agenda de reformas pueden ser factores que concordaron con un cambio incremental en la política exterior brasileña.

Durante el año 2017, el presidente Temer realizó trece intercambios ministeriales. Cuatro de ellos provenían de la discordancia de los ministros con su gobierno, como en los casos de los ministros de Cultura Marcelo Calero (PMDB) y Roberto Freire (PPS). Las denuncias de corrupción contra el presidente alejaron a algunos políticos y partidos de la base de apoyo al gobierno. La abundancia de ministros investigados en algún caso de corrupción también llama la atención (ver tabla 5). De los 22 ministerios mencionados, solo cinco no incluyen políticos citados en alguna investigación en curso, hecho que corrobora la percepción de la corrupción como problema central del país y la baja popularidad del presidente. La siguiente sección discute la implementación por parte del Ejecutivo de las enmiendas parlamentarias al presupuesto federal en el año 2017.

\section{El uso del presupuesto federal a través de enmiendas parlamentarias}

Algunos autores como Pereira y Mueller (2002) y Santos et al. (1997) ven la centralidad de la ejecución de las enmiendas individuales como un importante mecanismo del Ejecutivo para la obtención de apoyo político en la coalición partidista que sustenta al gobierno. El ministro de Salud, Barros (PP), afirmó, por ejemplo, que reservó en 2017, 500 millones de reales del presupuesto del ministerio para enmiendas de congresistas por orientación de Temer para usar como "moneda de cambio" con el Congreso Nacional (Valor Econômico2018). Sin embargo, la relación entre ejecución de enmiendas y apoyo legislativo al gobierno no es consensual en la literatura. Limongi y Figueiredo (2005) presentan una visión distinta sobre el asunto, argumentando que la liberación de recursos no explica el comportamiento de los parlamentarios en las votaciones nominales y, por consiguiente, el apoyo legislativo al gobierno. Hay diputados de oposición con enmiendas ejecutadas sin la esperada retribución en plenario, así como diputados de la base de apoyo del gobierno cuyas enmiendas previstas no se ejecutan (Limongi y Figueiredo 2005: 765). En la figura 2 se incluyen 
las enmiendas parlamentarias individuales agregadas por partido político ejecutadas por el Poder Ejecutivo en el año 2017.

Figura 2. Enmiendas parlamentarias al presupuesto ejecutadas por el Poder Ejecutivo en 2017

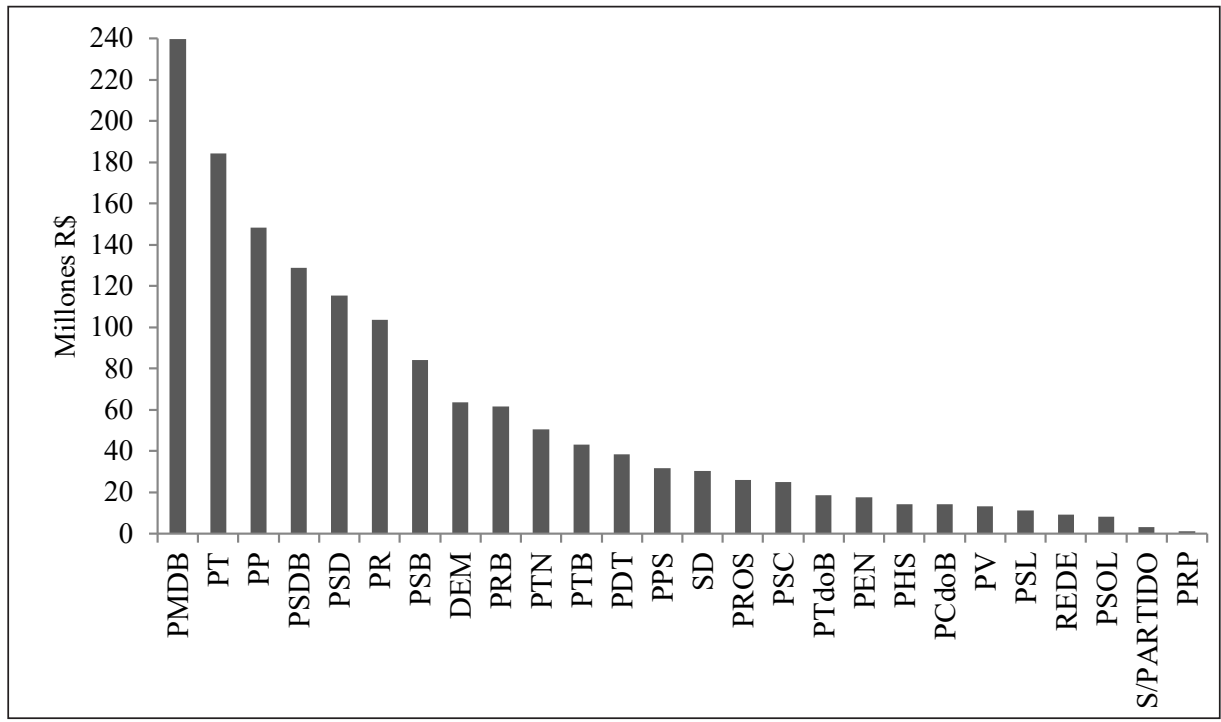

Fuente: Ministério do Planejamento (2018): https:/ / www1.siop.planejamento.gov.br/QvAJAXZfc/opendoc. $\mathrm{htm}$ ?document=IAS\%2FExecucao_Orcamentaria.qvw\&host=QVS\%40pqlk04\&anonymous=true.

El primer aspecto que llama la atención en la figura 2 es la posición del PT como segundo partido con más enmiendas ejecutadas en términos de valores, detrás del PMDB, partido del presidente. Es importante recordar que el PT, en la Cámara de Diputados en 2017, apoyó al gobierno en apenas el $24 \%$ de las votaciones en el plenario. Otros partidos que dejaron la base del gobierno durante el año, como el PSB, aparecen al frente de partidos altamente leales al gobierno en plenario, como el DEM. Los mayores partidos de las cámaras legislativas, independientemente de apoyar o no al gobierno, obtuvieron mayores valores ejecutados en las enmiendas parlamentarias. La figura 2 corrobora la percepción de baja asociación entre enmienda individual ejecutada y apoyo al Ejecutivo en el plenario. El Poder Ejecutivo, por controlar fuertemente la agenda presupuestaria, ejecuta enmiendas de parlamentarios de la oposición generalmente en consonancia con su propia agenda (Limongi y Figueiredo, 2005: 767).

En el caso del PT, la gran mayoría de enmiendas individuales ejecutadas se refiere al apoyo al mantenimiento de unidades de salud, elemento que concuerda con los gastos efectivos del Gobierno Federal en el mismo año. La figura 3 expone la distribución de los gastos efectivos del Gobierno Federal en el año 2017 entre las principales áreas de actuación del Estado brasileño. Es importante resaltar 
que esta figura excluye el gasto más voluminoso del presupuesto federal (cargas especiales) responsable de más de un billón de reales. Se optó por este criterio porque estas cargas engloban gastos no asociados con un bien o servicio generado en el proceso productivo, y generalmente se refieren a deudas o ejecuciones judiciales.

Figura 3. Gastos efectivos del Gobierno Federal por área en 2017

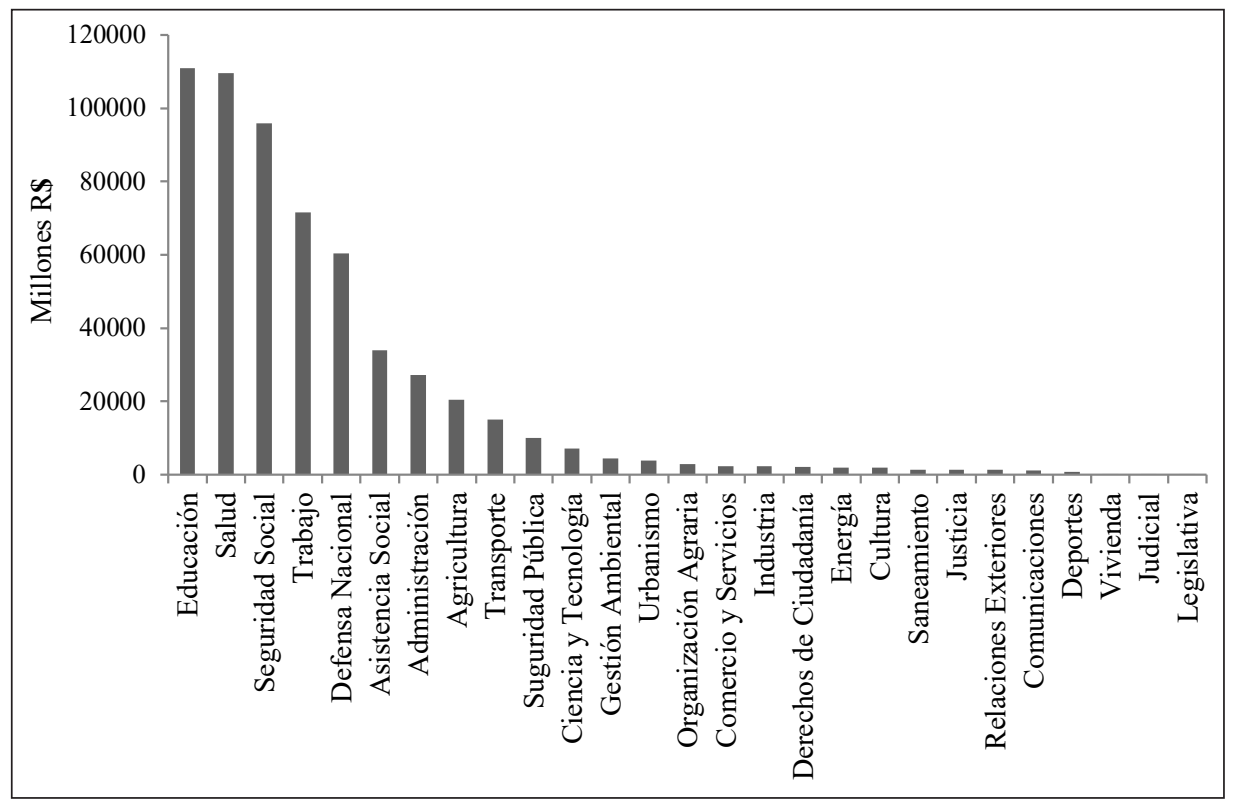

Fuente: Portal da Transparência: http:/ / www.portaldatransparencia.gov.br/PortalFuncoes.asp?Exercicio $=2017 \&$ Pagina $=1$.

Como se puede ver en la figura 3, la educación y la salud fueron los principales gastos del Gobierno Federal en el año, seguidos por la previsión social, trabajo y defensa nacional. Además de la cuestión constitucional, que determina gastos obligatorios en salud y educación, es posible argumentar que la salud fue una de las prioridades del gobierno en 2017, al menos en términos de gastos presupuestarios. En ese sentido, cuando observamos que las enmiendas individuales de parlamentarios del PT son mayoritariamente referentes a unidades de salud, se puede concluir que hay correspondencia con la agenda presupuestaria del gobierno. Los argumentos de Limongi y Figueiredo (2005) parecen explicar bien el caso del gobierno Temer, o sea, la ejecución de las enmiendas individuales de los parlamentarios no es instrumento fundamental del Poder Ejecutivo en la búsqueda de apoyo legislativo en el Congreso Nacional. 


\section{Cohesión ideológica de las coaliciones partidistas}

La distancia ideológica entre los partidos que componen la coalición gubernamental es un elemento que interfiere de manera significativa en la administración del apoyo legislativo del presidente (Montero 2009). Mientras más grande el nivel de polarización ideológica entre los partidos políticos, mayor es la dificultad de coordinación de las distintas agendas políticas de estos (Santos et al. 2014), elevando el costo de gestión de la coalición (Bertholini y Pereira 2017).

Utilizando conceptos y datos manejados por Power y Zucco (2012) y Bertholini y Pereira (2017) acerca del posicionamiento ideológico de los partidos políticos en el espectro político-partidario y el índice de costo de gerencia de coalición, respectivamente, en la figura 4 se exponen los últimos siete mandatos presidenciales en Brasil según la heterogeneidad ideológica de los partidos pertenecientes a la coalición de apoyo al gobierno y el respectivo índice de costo de gobierno.

Para determinar el grado de cohesión ideológica de las coaliciones de gobierno, aquí se adoptó la métrica propuesta por Bertholini y Pereira (2017: 537): el coeficiente de variación (una razón entre desviación estándar y media) de las ideologías de los partidos estimadas vía survey aplicado a los legisladores (Power y Zucco 2012). El índice de costo de gobierno (ICG) engloba la cantidad de ministerios que el presidente decide mantener en la administración federal, los recursos asignados entre los ministerios ocupados por los miembros de la coalición y el monto de enmiendas individuales ejecutadas de los parlamentarios (Bertholini y Pereira 2017: 539).

Figura 4. Cohesión ideológica de las coaliciones partidista y el índice de costeo del gobierno (1995-2017)

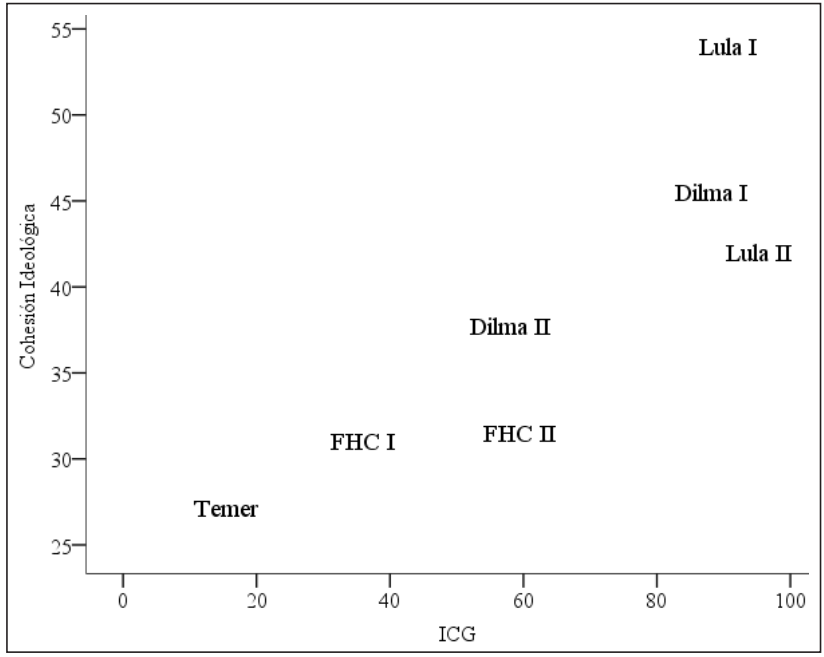

Fuente: Elaboración propia con datos de Bertholini y Pereira (2017) 
El primer aspecto a ser observado en la figura 4 es la correlación entre el costo de gobierno y la heterogeneidad ideológica de la coalición de gobierno. Cuanto mayor es la distancia ideológica de los partidos que componen la base de apoyo legislativo al gobierno brasileño, mayor es el costo para el presidente gobernar el país. Mientras los dos mandatos del presidente Lula y el primero de la presidenta Dilma representan el costo de gobierno más grande asociado con una elevada heterogeneidad ideológica, el gobierno del presidente Temer presenta el menor costo y la menor heterogeneidad ideológica en su base de apoyo.

Zucco y Lauderdale (2011) argumentan que desde la redemocratización hasta el último mandato del presidente Fernando Henrique Cardoso, la dimensión ideológica estaba correlacionada con la disposición de los partidos entre pertenecientes a la coalición de gobierno o no. Así, una única dimensión ideológica era capaz de determinar buena parte de los votos en la Cámara de Diputados de Brasil. Esto puede ser observado en la menor heterogeneidad ideológica de los dos mandatos del presidente Fernando Henrique Cardoso (FHC). En los gobiernos de Lula (2003-2010) y Dilma la situación cambió bastante y las dimensiones partidistas derecha-izquierda y gobierno-oposición dejaron de estar correlacionadas en el Congreso Nacional, elevando la heterogeneidad ideológica de la coalición partidista del gobierno. En el gobierno Temer, la situación es similar a los años de FHC, derecha e izquierda y gobierno y oposición se correlacionan, permitiendo a la gestión de Temer, con relativo bajo costo, un alto éxito legislativo.

En el presidencialismo de coalición brasileño, con una de las más altas fragmentaciones partidistas en el mundo, los riesgos de conflictos entre el Ejecutivo y el Legislativo pueden ser multiplicados o reducidos de acuerdo con las elecciones que el presidente haga para gestionar su coalición (Pereira 2017). Una importante variable para que el presidente tenga en cuenta es la preferencia ideológica de los partidos elegidos para integrar la base de gobierno. Además, la cantidad y calidad de ministerios compartidos con esos partidos también configuran parte de las decisiones presidenciales con consecuencias relevantes para el éxito legislativo del presidente y la relación entre los Poderes Ejecutivo y Legislativo en general. El gobierno Temer en 2017 es un buen ejemplo de ello. A pesar de tener más partidos en su base de apoyo -comparado con los otros gobiernos de la figura 4-, Temer fue el presidente de la serie que más distribuyó ministerios entre los partidos que lo apoyan, a diferencia del PT en los años de gobierno de Lula y Dilma, cuando el partido del presidente poseía la mayoría de los ministerios importantes.

Así, la distribución de ministerios entre la base de apoyo y la homogeneidad ideológica de los partidos que la componen garantizaron al presidente Temer la gobernabilidad en un momento de baja popularidad presidencial, de indicadores socioeconómicos muy negativos y de graves acusaciones por corrupción. La administración de los vastos recursos presidenciales de Temer fue eficiente y 
exitosa, posibilitando emprender profundas reformas en el país con el apoyo del Congreso Nacional.

\section{CONCLUSIÓN}

Elaño2017 representó una tímida mejora en algunosindicadores socioeconómicos de Brasil, como el crecimiento del 1\% del PIB, una inflación controlada y un superávit comercial. Sin embargo, los altos índices de déficit fiscal, desempleo y pobreza constituyen un escenario todavía muy negativo para la sociedad brasileña, propiciando un apoyo popular al gobierno extremadamente bajo. En el escenario socioeconómico desfavorable, las denuncias de corrupción contra Temer y muchos de sus ministros derribaron la popularidad del mandatario al $3 \%$ en el año, enfrentando un contexto político realmente difícil.

A pesar de las adversidades, el presidente logró aprobar importantes reformas legislativas y mantenerse en el cargo, contando con un amplio y disciplinado apoyo de la coalición partidista del gobierno en el Congreso Nacional. La reforma laboral, la tercerización y el rechazo de las dos denuncias de corrupción en su contra demostraron la fuerza legislativa de Temer. Los cambios relevantes que no necesitaban el Congreso Nacional también se implementaron en 2017, como en el caso de la política exterior, en donde la suspensión de Venezuela del MECOSUR y la solicitud de adhesión a la OCDE caracterizaron la modificación del posicionamiento brasileño en relación con gestiones pasadas.

Al año del impeachment a Dilma Rousseff, Temer demostró la elevada gobernabilidad que el presidencialismo de coalición brasileño puede generar. Por medio de la utilización de los recursos administrativos, presupuestarios y la formación de una coalición de partidos cohesiva desde el punto de vista ideológico, el Ejecutivo garantizó una elevada eficiencia en su relación con el Congreso Nacional.

Las elecciones presidenciales en relación a los partidos que integraron la base de gobierno y la distribución de ministerios relevantes entre los partidos de esta base son elementos claves en el multipartidismo exacerbado en Brasil. La paradoja es que el mismo sistema presidencialista de coalición que culminó en el impeachment de dos presidentes en 27 años de democracia, garantizó plena gobernabilidad a otros cinco mandatos presidenciales. En esta perspectiva, el gobierno Temer en 2017 es un excelente caso para concluir que la gestión de una coalición de gobierno mayoritaria y disciplinada en el Congreso Nacional es condición suficiente para que el presidente gobierne el país. El presidencialismo de coalición brasileño sigue vivo y respirando sin dificultades. 


\section{REFERENCIAS}

Abranches, Sergio. 1988. "Presidencialismo de coalizão: o dilema institucional brasileiro." Dados 31 (1): 5-38.

Amorim Neto, Otávio. 2006. "The presidential calculus: Executive policy making and cabinet formation in the Americas." Comparative Political Studies 39 (4): 415-440.

Arcaya, Godoy. 2003. "Parlamento, presidencialismo y democracia protegida." Revista de Ciencia Política 23 (2): 7-42.

Azevedo, Guilherme. 2017. "Eu [também] não sabia". UOL Notícias. Recuperado el 20 de marzo de 2018 de: https://www.uol/noticias/especiais/entrevista-fhc.htm\#temer-fez-mais-mudancas-do-que-eu-podia-imaginar.

Batista, Mariana. 2013. "O poder no Executivo: uma análise do papel da Presidência e dos Ministérios no presidencialismo de coalizão brasileiro (1995-2010)." Opinião Pública 19 (2): 449-473.

Batista, Mariana. 2017. "Taking portfolios difference seriously: a composite measure based on policy, office, and budget in Brazil." Brazilian Political Science Review 11 (1): 1-28.

Bertholini, Frederico y Carlos Pereira. 2017. "Pagando o preço de governar: custos de gerência de coalizão no presidencialismo brasileiro." Revista de Administração Pública-RAP 51 (4): 528-550.

Blondel, Jean. 1988. "Ministerial Careers and the Nature of Parliamentary Government: The Cases of Austria and Belgium." European Journal of Political Research 16 (1): 51-71.

Câmara dos Deputados. 2017. "Solicitação para instauração de proceso". Recuperado el 10 de abril de 2018 de: http://www.camara.gov.br/proposicoesWeb/fichadetramitacao?idProposicao $=2143164$

Confederación Nacional de la Industria (CNI). 2018, Abril de 2018. "Problemas e Prioridades". Recuperado el 05 de Abril de 2018 en: http:/ /www.portaldaindustria.com.br/ estatisticas/rsb-41-problemas-e-prioridades- para el 2018.

Chaisty, Paul, Nic Cheeseman, and Timothy Power. 2014. "Rethinking the 'Presidentialism Debate': Conceptualizing Coalitional Politics in Cross-Regional Perspective." Democratization 21 (1): 72-94.

Chasquetti, Daniel. 2001. "Democracia, multipartidismo y coaliciones en América Latina: evaluando la difícil combinación." En Tipos de presidencialismo y coaliciones políticas en América Latina, editado por Jorge Lanzaro. Buenos Aires: Consejo Latinoamericano de Ciencias Sociales/CLACSO, 319-359.

Chasquetti, Daniel. 2008. "Uruguay 2007: El complejo año de las reformas." Revista de Ciencia Politica 28 (1): 385-403.

Cheibub, José Antonio, Adam Przeworski, y Sebastián M. Saiegh. 2004. "Government Coalitions and Legislative Success under Presidentialism and Parliamentarism." British Journal of Political Science 34 (4): 565-587.

Dahlstrom, Carl y Birgitta Niklasson. 2013. "The Politics of Politicization in Sweden." Public Administration 91 (4): 891-907.

Eichbaum, Chris y Richard Shaw. 2007. "Ministerial Advisers, Politicization and the Retreat from Westminster: The Case of New Zealand." Public Administration 85 (3): 609-640.

Esposito, Ivan Richard. 2017. "Senado aprova MP que prorroga concessões; medida estava prestes a vencer". EBC Agencia Brasil. Recuperado el 9 de abril de 2018 de: http:/ / agenciabrasil.ebc.com.br/politica/noticia/2017-05/senado-aprova-mp-que-prorroga-concessoes-medida-estava-prestes-vencer.

Estadão Dados - Basômetro. 2018. "Tasa de apoyo de los partidos de base". Recuperado el 23 de marzo de 2018 de: http:/ / estadaodados.com/basometro/.

Fernandes, Daniela. 2017. "Os prós e contras de o Brasil entrar na OCDE, o 'clube dos ricos'." BBC Brasil. Recuperado el 16 de abril de 2018 de: http:/ / www.bbc.com/portuguese/ internacional-40140913.

Figueiredo, Argelina y Fernando Limongi. 1999. Executivo e Legislativo na nova ordem constitucional. Rio de Janeiro: Editora FGV. 
Figueiredo, Argelina, Denise L. Salles y Marcelo M. Vieira. 2009. "Political and Institutional Determinants of Executive's Legislative Success in Latin America". Brazilian Political Science Review 3 (2): 155-171.

Freitas, Andrea. 2016. O presidencialismo de Coalizão. Rio de Janeiro: Fundação Konrad Adenauer.

Gandra, Alana. 2017. "Pesquisa revela insegurança do brasileiro em relação ao futuro." EBC Agencia Brasil. Recuperado el 28 de abril de 2018 de: http:/ / agenciabrasil.ebc.com.br/ geral/noticia/2017-09/pesquisa-revela-inseguranca-do-brasileiro-em-relacao-ao-futuro.

Gómez, Manuel V. 2017. "A reforma da Espanha que inspirou Temer: mais empregos (precários) e com menores salarios." El País. Recuperado el 9 de abril de 2018 de: https: / / brasil.elpais.com/brasil/2017/04/27/internacional/1493296487_352960.html.

Lewis, David. 2007. “Testing Pendleton's Premise: Do Political Appointees Make Worse Bureaucrats?" The Journal of Politics 69 (4): 1073-1088.

Limongi, Fernando. 2006. "A democracia no Brasil: presidencialismo, coalizão partidária e processo decisório." Novos Estudos CEBRAP 76: 17-41.

Limongi, Fernando y Argelina Figueiredo. 2005. "Processo orçamentário e comportamento legislativo: emendas individuais, apoio ao Executivo e programas de governo." $D a-$ dos 48 (4): 737-776.

Mainwaring, Scott. 1993. "Presidentialism, Multipartism, and Democracy: The Difficult Combination." Comparative Political Studies 26 (2): 198-228.

Mainwaring, Scott. 1997. "Multipartism, Robust Federalism, and Presidentialism in Brazil," En Presidentialism and Democracy in Latin America, editado por Scott Mainwaring y Matthew Soberg Shugart. New York: Cambridge University Press, 55-109.

Mayntz, Renate y Hans-Ulrich Derlien. 1989. "Party Patronage and Politicization of the West German Administrative Elite 1970-1987: Toward Hybridization?" Governance 2 (4): 384-404.

Meirelles, Henrique. 2017, 20 de noviembre. "Meirelles vê 4\% de crescimento em 2018 devido à capacidade ociosa". Recuperado el 3 de Abril de 2018 de: http://www.valor.com. $\mathrm{br} / \mathrm{brasil} / 5199847 /$ meirelles-ve-4-de-crescimento-em-2018-devido-capacidade-ociosa-alta. Acesso em 03/04/2018.

Ministerio de Trabajo. 2017. "Contribuição Sindical". Recuperado el 12 de abril de 2018 de: http://acesso.mte.gov.br/cont_sindical/arrecadacao-da-contribuicao-sindical. $-2 . h$ tm.

Ministerio de Trabajo. 2018. "Evolução de Emprego do CAGED - EEC". Recuperado el 12 de abril de 2018 de: http://bi.mte.gov.br/eec/pages/consultas/evolucaoEmprego/ consultaEvolucaoEmprego.xhtml\#relatorioSetor

Montero, Mercedes García. 2009. Presidentes y parlamentos: ¿ quién controla la actividad legislativa en América Latina? Madrid: CIS.

Negretto, Gabriel L. 2006. "Minority Presidents and Democratic Performance in Latin America." Latin American Politics and Society 48 (3): 63-92.

Nolte, Detlef. 2003. "El Congreso chileno y su aporte a la consolidación democrática en perspectiva comparada." Revista de Ciencia Política 23 (2): 43-67.

Nunes, Felipe y Carlos R. Melo. 2017. "Impeachment, Political Crisis and Democracy in Brazil." Revista de Ciencia Política 37 (2): 281-304.

Orair, Rodrigo Octávio. 2016. Investimento público no Brasil: trajetória e relações com o regime fiscal. No. 2215. Texto para Discussão, Instituto de Pesquisa Econômica Aplicada (IPEA). Recuperado el 5 de abril de 2018 de: http://repositorio.ipea.gov.br/bitstream/11058/6873/1/TD_2215.PDF.

Pereira, Carlos. 2017, 29 de octubre. "Temer é o presidente mais eficiente na relação com o Congresso desde 1995". Recuperado el 3 de marzo de 2018 de http://www1.folha. uol.com.br/ilustrissima/2017/10/1930813-temer-e-o-presidente-mais-eficiente-narelacao-com-o-congresso-desde-1995.shtml. 
Pereira, Carlos y Bernardo Mueller. 2002. “Comportamento Estratégico em Presidencialismo de Coalizão: As Relações entre Executivo e Legislativo na Elaboração do Orçamento Brasileiro." Dados 45 (2): 265-301.

Pereira, Carlos y Marcus A. Melo. 2012. “The Surprising Success of Multiparty Presidentialism." Journal of Democracy 23 (3): 156-170.

Pérez-Liñán, Aníbal y John Polga-Hecimovich. 2012. “Political Elites, Democratic Breakdown, and Presidential Instability in Latin America". Ponencia presentada en International Political Science Association (IPSA) Conference, Madrid, 8-12 de julio.

Power, Timothy y Cesar Zucco. 2012. "Elite Preferences in a Consolidating Democracy: The Brazilian Legislative Surveys, 1990-2009." Latin American Politics and Society (54) 4: $1-27$.

QoG Institute. 2015. “Quality of Government Social Policy Dataset, QoG Social Policy Dataset". Recuperado el 28 de marzo de 2018 de: http://www.edac.eu/indicators_desc. cfm?v_id=203.

Rauch, James y Peter Evans. 2000. "Bureaucratic Structure and Bureaucratic Performance in Less Developed Countries." Journal of Public Economics 75 (1): 49-71.

Requião, Roberto. 2017, 3 de agosto. "Requião diz que adesão do Brasil a Ocde é a volta do complexo de Vira-Lata." Recuperado el 17 de abril de 2018 de: http:/ /www.robertorequiao.com.br/requiao-diz-que-adesao-do-brasil-a-ocde-e-a-volta-do-complexo-devira-lata/.

Ribeiro, Pedro Floriano, Amanda Vizoná y Priscilla Leine Cassotta. 2016. "Brasil: un país en compás de espera." Revista de Ciencia Política 36 (1): 51-74.

Rudalevige, Andrew. 2002. Managing the President's Program: Presidential Leadership and Legislative Policy Formulation. Princeton: Princeton University Press.

Santos, Manoel Leonardo; Aníbal Perez-linan y Mercedes García Montero. 2014. "El control presidencial de la agenda legislativa en América Latina." Revista de Ciencia Política 34 (3): 511-536.

Santos, Maria Helena de Castro, Érica Massimo Machado y Paulo Eduardo Nunes de Moura Rocha. 1997. “O Jogo Orçamentário da União: Relações Executivo-Legislativo na Terra do Pork-Barrel". En Reforma do Estado e Democracia no Brasil, editado por Eli Diniz y Sergio Azevedo. Brasília: Editora da UnB/ENAP.

Soares de Lima, Maria Regina. 2005. "A política externa brasileira e os desafios da cooperação Sul-Sul." Revista Brasileira de Política Internacional 48 (1): 25-59.

Stepan, Alfred y Cindy Skach. 1993. "Constitutional Frameworks and Democratic Consolidation: Parliamentarianism versus Presidentialism." World Politics 46: 1-22.

Valor Econômico. 2017. "Barros: Temer usou R \$ 500 milhões como moeda de troca com Congresso." Valor. Recuperado el 16 de abril de 2018 de: http:/ / www.valor.com.br / politica/5247009/barros-temer-usou-r-500-milhoes-como-moeda-de-troca-com-congresso.

Zucco, Cesar y Benjamin Lauderdale. 2011. "Distinguishing between influences on Brazilian legislative behavior." Legislative Studies Quarterly 36 (3): 363-396.

\section{Apéndice A}

DEM - Demócratas

PC do B - Partido Comunista de Brasil

PDT - Partido Democrático Laboral

PEN - Partido Ecológico Nacional

PHS - Partido Humanista de la Solidaridad

PMDB - Partido del Movimiento Democrático Brasileño

PP - Partido Progresista

PPS - Partido Popular Socialista

PR - Partido de la República 
PRB - Partido Republicano Brasileño

PROS - Partido Republicano del Orden Nacional

PRP - Partido Republicano Progresista

PSB - Partido Socialista Brasileño

PSC - Partido Social Cristiano

PSD - Partido Social Democrático

PSDB - Partido de la Social Democracia Brasileña

PSL - Partido Social Liberal

PSOL - Partido Socialismo y Libertad

PT - Partido de los Trabajadores

PTB - Partido Laborista Brasileño

PTN - Partido Laborista Nacional

PV - Partido Verde

SD - Solidaridad

Pedro Feliú Ribeiro es profesor de Relaciones Internacionales en la Universidad de São Paulo (IRI-USP), investigador del Centro de Estudios de Negociaciones Internacionales (CAENI-USP) y Doctor en Ciencia Política por la Universidad de São Paulo. Actualmente es vice-presidente del programa de posgrado de IRI-USP. Correo electrónico: pedrofeliu@usp.br 